\title{
The Role of Guidelines in Interventional Pain Medicine: Let Us Separate Apples and Oranges
}

\author{
Laxmaiah Manchikanti, MD*, David Kloth, MD** and Vijay Singh, MD*
}

Practice guidelines are not only an ancient tradition, but they are a fact of life. The first guidelines were developed in the 1840s, shortly after the use of anesthesia was first demonstrated. Even though practice guideline development has spawned an impressive and overaggressive literature of its own, many unanswered questions exist with regard not only to practice parameters and guidelines in general, but in particular with the application of interventional techniques in managing persistent pain.

In spite of the great potential of clinical practice guidelines, and the involvement of numerous medical societies and physician groups, there is still a great debate within the profession not only about the pros and cons of the development and usage of the guidelines, but also conflicting and controversial opinions on both sides of the issue, ie, providers and patients vs payors.

This article discusses the development, usage, advantages, disadvantages and the implications of practice guidelines to interventional pain medicine specialists.

Keywords: Interventional techniques, persistent pain, chronic pain, practice guidelines
"As new discoveries are made, new truths dis covered, and manners and opinions changed, with the change of circumstances, institutions must advance also to keep pace with the times..."

- Thomas Jefferson

The use of practice guidelines in medicine is not new (115). In fact, nearly all generic rules, treatments, indications, and criteria in the medical text books can be considered as practice guidelines. The first guidelines were specific to the practice of anesthesia, concerned themselves with overall patient safety and effective technique for preventing anesthetic mishaps and were developed in the 1840s, shortly after the use of anesthesia was first demonstrated (16-25). Since then, through the new millennium, nearly 2500 practice parameters have been developed and used in the practice of medicine in the United States. These parameters or guidelines have been developed by numerous groups spearheaded by Health Maintenance Organizations (HMOs), third-party payors, and the federal government, followed by medical specialty so-

From the *Pain Management Center of Paducah, Paducah, KY, **Connecticut Pain Care, Danbury, CT and "Pain Diagnostic Associates, Niagra, WI. Address correspondence: Laxmaiah Manchikanti, MD, 2831 Lone Oak Road, Paducah, Kentucky 42003. Email: drm@apex.net cieties, various physician groups, individual hospitals, and a multitude of carriers within the federal health care programs (1-3, 27-53). In addition, this has developed into an industry with numerous commercial organizations entering this market. Even though practice guideline development has spawned an impressive and overaggressive literature of its own, including manuals on how to develop practice guidelines and publications designed to assist clinicians in the use of these guidelines, many unanswered questions exist with regard not only to practice parameters and guidelines in general, but in particular the management of persistent pain including various interventional techniques $(9,13,14,44,49-69)$. Unfortunately, some of the most clinically significant and widely publicized practice guidelines relating to issues of pain management, were developed either by commercial organizations, third-party payors, HMOs, or local carriers for federal health care programs. In addition, many of these guidelines are limited to acute pain management, and management of cancer pain Thus, given the extraordinary activity in guideline development in general, and pain management in particular, it is not only incumbent on the pain management community but it is mandatory to understand the rationale, development, implementation, and effectiveness of practice guidelines in managing persistent pain with interventional techniques, and also to be directly involved in the development of these guidelines. 
Much confusion exists about the difference between a guideline and a pathway; the terms are often used interchangeably (51). While practice guidelines are systematically developed statements to assist practitioner and patient decisions about appropriate health care for specific clinical circumstances, in contrast, clinical pathways, are tools to coordinate the time-dependent progress of a typical uncomplicated patient across many clinical departments that is specific to the condition or disease being managed (51). Whether it is the development of guidelines or pathways, there is always criticism. However, once again we are reminded that: "failure to prepare is preparing to fail". When we fail to prepare, ie, fail to develop guidelines, we will be forced to follow the guidelines developed by people who not only fail to understand interventional pain medicine, but also have vested interests in the business aspects of medicine. In the early 70s, Cochrane (27) a British physician established the need for practice guidelines by lamenting the fact that most medical decisions were not based on a solid evidentiary foundation. He also emphasized the importance of randomized, controlled trials in guiding decisions about health care (70). Unfortunately, most interventional pain physicians, similar to other physicians in the United States, are not only not trained to critically appraise the medical literature but also depend on the teachings of their seniors and anecdotal experiences, resulting in not only variable perceptions and interpretations, but also highly variable outcomes of interventions. Consequently, there is always a friction and suspicion among patients, third-party payors, and physicians with regards to the effectiveness of various treatment modalities. In fact, it is alleged that as many as $30 \%$ of the procedures performed in the United States do not meet appropriate criteria, thus adding to the cost of health care in the United States $(11,15,17,71-$ 79). As a result, the US health care policy makers and payors not only seized on guidelines as a magic bullet for eliminating unnecessary care and its associated costs, but also used this approach as a cure-all for the ailing health care system in the United States, resulting in the deleterious effects of extensive management of physician behavior and patient care (75).

It is important to understand the philosophy behind the development of the guidelines by health care policy makers or commercial agencies. They are mainly motivated by administrative convenience and business incentives rather than quality assurance and consideration of effectiveness of patient care. The Institute of Medicine (IOM) of the United States National Academy of Sciences in 1992 identified multiple roles of guidelines which included cost control, quality assurance, enhancing access to care, patient empowerment, professional autonomy and medical liability (28). An additional role of the present guidelines is to help insurance carriers understand when to use the interventional modalities. This is not just an exercise of the review of the literature, which they can (and do) do themselves. These guidelines are meant to include advice on when, how, and how often to perform the procedures on almost each and every technique in a more specific and a scientific manner as close as we can get to the available evidence. We all understand that there is a gap between scientific aspects of the medicine and the clinical practice of medicine, which is an art. In recent years, medicine, which has been long recognized as a subtle admixture of science and art, has been moving in the direction of becoming an exact science as new tools and techniques have been developed to help practitioners understand better what works and what doesn't (79). This reference is made to evidence-based medicine, that is, making use of the best existing evidence as found in sources such as published reports and meta-analyses to make decisions about the care of patients. While this practice is spreading and probably gaining acceptance in the medical community, insurers are utilizing this to help define medical necessity, a thorny issue. However, evidence-based medicine, as discussed in the guidelines, is an extremely difficult task in interventional pain medicine. In addition, there is the inherent bias of a developing agency, whether it is an HMO, PPO, local Medicare carrier, or even Health Care Financing Administration, as it all depends on the membership and purpose of these organizations developing the guidelines. Consequently, the same evidence may be interpreted in several different manners. And we must remember that science in general, and medical science in particular, is never a finished product. It is a process of groping through the ignorance one observation at a time. An ancient Indian fable aptly illustrates the nature of the problem:

Five blind men who knew nothing about elephants went into the forest in search of one. The first to touch the elephant encountered the leg, and declared, "An elephant is like a tree.” The next found the tail, and said, "You are wrong. An elephant is like a rope." The third reached the snout and affirmed, "You are both wrong. An elephant is like a snake.” The fourth bumped into the side of the beast, and berating the others shouted, "You are all wrong. An 
elephant is like a wall." The fifth was brushed by the ear, and demanded, "What are you saying? An elephant is like a curtain.”

And so it is with the approach to the subject of pain and evidence-based medicine. Different aspects tend to be grasped by different organizations and for that matter, different specialists using different concepts leading to different conclusions. Sadly, there is also difference among pain management specialists themselves. While all the pain specialists understand the need for treatment, there is unfortunate division between those who advocate the "biopsychosocial approach," however, managing pain without "bio", thus using only "psychosocial approach" and adapting to the pain, in contrast to those who perform "interventional" procedures to relieve the pain utilizing a complete "biopsychosocial approach" or a "biological approach”. Since on a face value, the psychosocial approach appears to be more cost effective than the interventional approach, it is necessary for interventionalists to provide, not only the evidence, but also the guidance. "Bio-psychosocial approach" without the "bio" component also assists some of the physicians to advance their ego as this model allows a psychodynamic exit from the frustration of not being able to find an organic cause for the pain, and it also gives the insurer a Teflon coating to protect them when refusing care. Thus, two specialists practicing pain medicine have diametrically opposite opinions when a psychosocial believer is called upon to review the work of an interventionalist. The situation may be philosophically analogous to inviting a Protestant minister to review to doctrinal teaching of a Catholic priest, or vice versa. Hippocratic oath states that "-I will practice medicine with conscience and dignity. The health and life of my patient will be my first consideration.--" It is therefore the duty of the physician to benefit the patient. The Hippocratic oath does not address gaps in scientific knowledge, thus these should only be bridged by experience and reason, considering the risk versus the benefit known when it is not proven rigorously on a scientific basis. The major goal of these guidelines is to avoid traditional barriers and make them compatible with clinical practice.

In spite of the great potential of the clinical practice guidelines, and the involvement of numerous medical societies and physician groups, there is still great debate within the profession not only about the pros and cons of development and usage of guidelines but also conflicting and controversial opinions on both sides of the issue i.e, pro- viders and patients Vs payors. Widely described positive effects of clinical practice guidelines as described by Walker et al (26) (with modifications and additions), are to assist:
- Patients in making informed health care deci- sions, Physicians in using appropriate health care tech- nologies,
Physicians in identifying and reducing so-called inappropriate care,
- Physicians in making cost-effective health care decisions,
- Third-party payors in utilization review, perfor- mance rating, and reimbursement decisions, In the development of clinical indicators used to assess organizational competence and identify aberrant practitioners, Physicians and organizations to improve clini- cal practice, quality of care, and access to much needed medical services,
- In lowering not only malpractice litigation costs by improving the quality of care but also to serve as an "affirmative defense" in malpractice liti- gation,
- In developing medical text books and other edu- cational materials around the guidelines, and To have a well reasoned and well developed docu- ment to present to payors.

Thus, many medical professionals see the guidelines as the best hope for accommodating the demands not only for the quality of care at the lowest possible price, but also getting involved in the development of these guidelines $(17,29,49,51,74,75)$. In addition, many physicians considered the practice guidelines not as a threat to professional autonomy but as a valuable addition or adjunct to the complex task of medical decision making (29). Eddy (29) observed that, "practice policies present a powerful solution to the complexity of medical decisions. They free practitioners from the burden of having to estimate and weigh the pros and cons of each decision. They can connect each practitioner to a collective consciousness, bringing order, direction and consistency to their decisions." He also stated that practice policies not only provide an intellectual vehicle through which the profession can distill the lessons of research and clinical experiences and put the knowledge and preferences of many people into conclusions about appropriate practices but also provide a natural pathway to convey that information to practitioners. Thus, practice policies may be considered as a 
central component to effective quality medical practice as what a conductor is to an orchestra. It also has been stated that practice guidelines, " are in effect, what the clinician would create personally if he or she had the time and resources to accomplish a full evaluation alone - - guidelines summarize the collective as determined scientifically" (26). Thus, in spite of differences some physicians believe that the art of medicine is preserved in tailoring of clinical practice guidelines to individual patient situations. Practice guidelines also have other drawbacks. They are not appropriate for all patients and often address only uncomplicated and homogenous patient groups (51). Additionally, they may be out of date by the time they are implemented or conflict with other published guidelines. On many occasions, guidelines are often vague with no specific wording that leaves much room for interpretation. An approach described in the guidelines may lead the physician to "cookbook medicine" with an unappetizing menu of choices. In addition, physicians who are expected to use the guidelines but are not familiar with the evidence upon which they are based, are unlikely to follow the guidelines. However, physicians should realize that the same is true for guidelines that appear to be driven solely by economic motives, such as the guideline that calls for three epidural injections without considering the patient diagnosis, physician opinion, or patient's functional status. Guidelines developed by a specific group of physicians practicing the same type of medicine are not only comprehensive but also are acceptable for that group of physicians, thus increasing the probability of appropriate implementation.

However, the controversies do not stop here. The critics of practice guidelines claim that these rob the physician of clinical autonomy, resulting not only in the practice of cookbook medicine, but some practitioners feel that they are in trenches, and guidelines do not represent their views (18, 26, 51, 76-79). Further criticism also surrounds the fact that practice guidelines may stifle innovative medical practice and the application of new technologies, may not reduce costs as much as anticipated, and adversely effect the research activity $(30,31)$. Yet, some others believe that the guidelines may lead to a rash of lawsuits and increased liability exposure for physicians, justifiably for appropriate reasons, failure to follow practice guidelines (80, 81). According to Walker et al (26), the most commonly mentioned disadvantages or negative effects of guidelines (with modifications and additions) are that the practice guidelines may:

- Lead to "cookbook medicine",

- Stifle innovative medical practice and the appli- cation of new technologies, and reduce research, Increase medical costs by identifying interventions that are used under,

Cost reductions may not be substantial and may not outweigh costs of developing and updating guidelines,

Contribute to disinterest in medicine as a carrier thus leading to decline of quality of the physician,

Provide inculpatory evidence in malpractice cases and increase malpractice litigation and costs or both,

- Not represent the prevailing practice of medicine,

Be interpreted differently by not only by different organizations but also by physicians and nonphysicians, thus making it a legal issue rather than a medical issue,

Lead to reduced patient access, and

Lead to in appropriate quality of care by reducing physician autonomy leading to "cookbook medicine", leading to ineffective use of the knowledge, and training of the physician and ignoring innovations.

With the above description in mind, we should realize that each group or organization which engages in the development of practice guidelines, including the American Society of Interventional Pain Physicians, does so with fundamental underlying objectives (49, 50, 51-53, 74, 78, 81, 82). Third-party payors and the HMOs approach the process of clinical practice guideline development from the standpoint of controlling or reducing health care costs whereas physician groups and medical specialty societies approach the guideline development with their stated objectives for the improvement of the quality and access of patient care $(18,49,50,51,74,75)$.

Regardless of the motivation of developing practice guidelines, there is general consensus on the attributes that practice guidelines should possess for maximum effectiveness thus providing a safety net. These characteristics include validity, reliability, applicability, flexibility, clarity, multidisciplinary development process, provisions for review and revision and clear documentation of the evidence on which the standard is based (76, 77, 80-84). Even though the objectives of the guidelines to develop guidelines attempt to insure that a policy is accurate, accountable, predictable, defensible, and usable, a wide range of controversies, criticisms, bias exist not only in the development but also in the interpretation of the guidelines 
(1-6, 8, 10, 11, 13-15, 18, 27, 29, 44-46, 52, 55-57, 66, 76, 77, 79, 85, 86). Thus, the development of the guidelines by the American Society of Interventional Pain Physicians may not only be accepted but appreciated by supporters of interventional pain management but we should be realistic and braced to face the criticism that these guidelines are developed by an organization representing the interests of interventional pain physician, thus, reportedly in the interest of these physicians. The specific advantages of these guidelines $(49-51,74)$ are that they describe not only the purpose, rationale, and importance, but also the methodology and patient population, pathophysiologic basis, and various interventional techniques utilized in the management of chronic pain including rationale, outcomes, and cost-effectiveness. It also explicitly provides guidance on clinical practice with clinical algorithms for comprehensive evaluation and management, and algorithms for the application of interventional techniques in conservative care of chronic spinal pain. These guidelines do not constitute inflexible treatment recommendations, and the spirit of the guidelines is that the provider will establish a plan of care on a case-by-case basis taking into account an individual patient's medical condition, personal needs, and preferences, and the physicians own experience. While guidelines do recognize that, based on an individual patient's needs, treatment from that outline in the guidelines will be warranted, these are the only guidelines which discuss extremely difficult issues of cost-effectiveness, frequency and number of injections or interventions, addressing combination of blocks or interventions, and number of interventions per setting. Best of all, these guidelines are developed by clinicians practicing interventional pain medicine, including those in trenches. This is in contrast to numerous other guidelines which either ignore the difficult issues, do not make recommendations or make recommendations without clinical applicability and are developed by special interest groups, on many occasions with little or no practical experience in practice of interventional pain medicine.

Over the last ten years, due to increasing pressure for clinical accountability and effectiveness, over 10 practice guidelines have been introduced to address the treatment of persistent pain. These included Guidelines for Management of Acute Low Back Pain (44), Epidural Use of Steroids in the Management of Back Pain (47, 48, 53, 54), "Whiplash" and its Management (46), Practice Guidelines for Chronic Pain Management (66), Performance of Spinal Injection Procedures (67), Interventional Techniques in the Management of Chronic Pain (49), Management of Chronic Pain in Older Persons (58), and Man- agement of Chronic Pain Syndrome Patients (59, 60). Other guidelines are specific for management of migraine headaches (61-63), sickle cell disease (64), and complex regional pain syndromes (65). While some of these guidelines are well publicized, others lack familiarity by physicians and patients alike. Among the well known guidelines, Clinical Practice Guideline \#4 an AHCPR publication describing acute low back problems in adults has faced substantial criticism resulting in publication of a book (52). Many of the guidelines do not offer practical information for physicians to follow $(45-48,54,66)$, Guidelines for the Performance of Spinal Injection Procedures was related to the diagnostic blocks of facet joints (67), Guidelines for Management of Chronic Pain in Older Persons and Chronic Pain Syndrome Patients (58-60) are neither well known nor accepted, and many other guidelines are syndrome related with limited application. In contrast, the guidelines developed by the American Society of Interventional Pain Physicians, formerly the Association of Pain Management Anesthesiologists, describing Interventional Techniques in the Management of Chronic Pain: Part 1.0, was widely disseminated to the membership, as well as some insurance carriers. Some of the aspects of these guidelines were incorporated into Medicare Guidelines in few states.

Review of all these guidelines indicate that they are a mixture of consensual and evidence-based recommendations. All the guidelines have in common a multidisciplinary team approach. However, these guidelines also possess numerous philosophical and practical differences. Interventionists feel that the guidelines describing the interventional pain procedures are based on evidence and consensus similar to guidelines developed by behavioralists $(49,50,52,74)$. Sanders (87) felt that the practice guidelines that applied the most stringent definition for adequate evidence were by Sanders et al $(59,60)$ describing management of chronic non-malignant pain syndrome patients. Sanders (87) described that such stringency led to noticeably more conservative treatment recommendations by these two sets of guidelines compared with others. Guidelines by Sanders et al $(80,81)$ do not recommend the use of opioids or invasive procedures in chronic pain syndrome patients, citing an obvious absence of evidence to do so. However, Sanders (87) expanded by stating that, "The more a given set of guidelines used lower quality evidence (eg, case studies) and/or expert consensus, the more treatment methods were recommended" citing American Society of Anesthesiologists ASA guidelines (66). He also stated that, "Practice guidelines from the ASA (57), and those of American Geriat- 
rics Society (58) make far more liberal recommendations about opioid and invasive procedure usage based on weak evidence (eg, poorly controlled outcome and case studies), as well as more reliance on expert consensus and common practice. Contrary to these assertions, the evidence which is in existence for managing so called chronic pain syndrome patient population with multidisciplinary or behavioral management does not only contradict these assertions, but also always has not been shown to be superior to the evidence for interventional techniques (9, $49,52-57,74,85,88-118)$. However, in separating apples and oranges, many physicians do not remember the difficulties related to randomized, controlled trials with interventional procedures and surgical interventions, and publications of so-called "peer reviewed" literature (119124). "Peer review" is different for each provider setting. Chiropractors and psychologists rarely have subspecialty differences and the literature is published without controversy. In contrast, first, the medical profession is composed of multiple specialties and numerous subspecialties. Second, pain medicine itself is a mixture of numerous factors, philosophically dominated by outspoken behavioralists and academicians, composition of which also represents not only the control of journals but also the publications. Thus, inherent bias exists against interventional pain medicine.

In addition, Concato et al (125) described that in the hierarchy of research designs, the results of randomized, controlled trials are considered to be evidence of the highest grade, whereas observational studies are reviewed as having less validity because they reportedly as a whole overestimate treatment effects. However, their results showed that randomized, controlled trials, observational studies, and hierarchy of research designs showed the average results of the observational studies to be remarkably similar to those of the randomized, controlled trials, and concluded that the results of well-designed observational studies do not systematically overestimate the magnitude of the effects of treatment as compared with those in randomized, controlled trials on the same topic. However, no such review is available with analysis of interventional techniques in pain management even though such a study is underway at the present time. Thus, it needs to be seen if the conclusions of Schulz et al (126) showing the empirical evidence of bias without randomization overestimating the treatment effect by $30 \%$ to $41 \%$ and lack of double-blinded protocol in the study overestimating the treatment effect by $17 \%$. It has been well described that clinical trials of efficacy of commonly used interventions in managing low back pain are described to have a methodological quality of fair to poor $(88,89)$. In addition, an inherent bias exists in reviewing the studies of interventional pain medicine when this review is not performed by interventional pain medicine specialists, as most of the studies of interventional pain procedures have been conducted by multiple speciality groups rarely including pain specialists and without radiographic control, especially in the case of epidural steroid injections, which essentially leads to not only the misinterpretation and misrepresentation of the evidence, but also miscommunication and, finally, obviously affects the patient care. Thus, it is a sorrowful situation without a solution in the near future. Therefore, regardless of the desire to achieve substantial impartial, scientifically based recommendations, guidelines can be influenced by clinical practice and personal philosophy of the authors and influence of special interest groups.

While we have completed the most crucial phase of developing and revising the guidelines for interventional techniques in managing persistent pain, and we believe that these guidelines are well founded and well formulated based on scientific evidence which is accurate accountable, predictable, defensible and useful, they will be of little or no use unless they are placed into the hands of practitioners and payors, so then, hopefully, the practitioners will conform to the guidelines recommendations and the payors to change their philosophies and accept the guidelines $(1,56,57)$. Hence, the first step in implementing a practice guideline is communicating it to the interested audiences, including consumers, health care practitioners, health care industry, policy makers, researchers, and even the press (84). Clearly, our organization has a daunting responsibility of disseminating the guidelines to the audiences. However, the responsibility does not end there. The guidelines as well as the recommendations made in the guidelines remain mute unless specific studies are developed to encourage the assimilation of practice guidelines into the day-to-day practice of individual physicians (127). However, the question always asked is, "are the guidelines effective?". This remains an openly debated question. We do not have any evidence for guideline usage in interventional pain medicine. However, the outcome studies on other guidelines yielded mixed results $(1,128-133)$.

These issues of problems with methodological quality of clinical guidelines in the peer-reviewed medical literature was evaluated by Shaneyfelt et al (77). They reviewed the methodological quality of clinical guidelines in the peer-reviewed medical literature with evaluation of 279 
guidelines developed by 69 different organizations and published from 1985 to 1997 concluding that these guidelines do not adhere to establish methodological standards. They added that while all areas of guideline development need improvement, the most work is needed in the identification, evaluation and synthesis of scientific evidence. Needless to say, we have attempted to adhere to all the standards and met many of the standards as established by Shaneyfelt et al (77). Many of the guidelines developed thus far were developed at a cost of tremendous effort and resources to review the assessment and treatment literature to develop so-called evidence-based guidelines to treat various conditions. However, a serious examination of the guidelines shows that about $85 \%$ of the recommendations are not based on any significant evidence (66). We hope, these guidelines of interventional techniques will fill the gap.

\section{CONCLUSION}

When considering clinical practice guidelines, interventional pain specialists should analyze and accept advantages and disadvantages, pros and cons, benefits and risks, patient access vs physician interests, cost-effectiveness vs innovations not only with extreme caution and diligence but also with fairness. Authors believe that these guidelines are extremely useful in the practice of interventional pain medicine not only with regards to demonstrating clinical effectiveness but also cost-effectiveness, and with improvement in the quality of care and patient access.

In conclusion, these guidelines and review of evidence show that: "Evidence is in the eyes of reviewer" synonymous to "Beauty is in the eyes of the beholder," and "Let us not presume everything is a nail, just because we have a hammer."

\section{REFERENCES}

1. Kelly JT, Toepp MC. Practice parameters: development, evaluation, dissemination, and implementation. QRB Qual Rev Bull 1992; 18:405-409.

2. American Medical Association, Office of Quality Assurance and Health Care Organizations: Directory of Practice Parameters. American Medical Association, Chicago, 1989.

3. Swartout JE. American Medical Association Office of Quality Assurance and Health Care Organizations: Directory of Practice Parameters. American Medical Association Chicago, 1992.
4. Committee to Advise the Public Health Service on Clinical Practice Guidelines, Institute of Medicine. Field MJ, Lohr KN (eds). Clinical Practice Guidelines. Directions of a New Program. National Academy Press; Washington, 1990.

5. Harris JS. Development, Use, and evaluation of clinical practice guidelines. JOEM 1997; 39:23-34.

6. Woolf SH. Practice guidelines: A new reality in medicine. I. Recent developments. Arch Intern Med 1990; 150:1811-1818.

7. Woolf SH. Practice guidelines, a new reality. medicine, II. Methods of developing guidelines. Arch Intern Med 1992; 152:946-952.

8. Bombardier C, Esmail R, Nachemson AL et al. The Cochrane collaboration back review group for spinal disorders. Spine 1997; 22:837-840.

9. McQuay H, Moore A. An evidence-based resource for pain relief. Oxford University Press. Oxford, New York, 1998.

10. Turk MA. Practice guidelines. In: The nonsurgical management of acute low back pain. Gonzalez EG, Materson RS (eds). Demos Vermande, New York 1997, pp 5-14.

11. Leape LL. Practice guidelines and standards: An overview. QRB Qual Rev Bull 1990; 16:42-49.

12. American Medical Association. Attributes to guide the development of practice parameters. Chicago: American Medical Association 1994.

13. McQuay H, Moore A. Introduction: An evidence based resource for pain relief. Oxford University Press, Oxford, New York, 1998: pp 1-4.

14. Sackett D, Richardson WS, Roseberg W et al. Evidence based medicine. Churchill Livingstone, Philadelphia, 1996.

15. Carter A. Clinical practice guidelines. Can Med Assoc $J$ 1992; 147:1649-1650.

16. Tinker JH, Dull DL, Caplan RA. Role of monitoring devices in the prevention of anesthetic mishaps: A closed claims analysis. Anesthesiology 1989; 71:541546.

17. Shomaker TS. Practice policies in anesthesia: a foretaste of practice in the twenty-first century. Anesth Analg 1995:388-403.

18. Shoemaker TS. Practice guidelines for pain management. In: Ashburn MA and Rice LJ (eds), The Management of Pain. Churchill Livingstone. Philadelphia, 1998, pp 205-226.

19. Pierce EC. Historial perspectives. In Pierce EC, Cooper JB (eds): Analysis of Anesthetic Mishaps. Int Anesthesiol Clin 1984; 22:1.

20. Pierce CE. The development of anesthesia guidelines and standards. QRB Qual Rev Bull 1990; 16:61-64.

21. Snow J. On the fatal cases of the inhalation of chloroform. Edinburgh Med Surg J 1849; 72:75.

22. Guidelines for Patient Care in Anesthesiology. American Society of Anesthesiologists, Park Ridge, 1968. 
23. Standards for Basic Interactive Monitoring. Approved October 21, 1986, as amended October 23, 1993. American Society of Anesthesiologists, Park Ridge, 1993.

24. Eichhorn JH, Cooper JB, Cullen DJ et al. Standards for patient monitoring during anesthesia at Harvard Medical School. JAMA 1986; 256:1017-1020.

25. Caplan RA, Posner KL, Ward RJ, Cheney FW. Adverse respiratory events in anesthesia: A closed claims analysis. Anesthesiology 1990; 72:828-833.

26. Walker RD, Howard MO, Lambert MD et al. Medical practice guidelines. West J Med 1994; 161:39-44.

27. Cochrane AL. Effectiveness and efficiency. Random reflections on health services. Nuffield Provincial Hospitals Trust, London, 1972.

28. Field MJ, Lohr KN. Institute of Medicine, Committee on Clinical Practice Guidelines: Guidelines for Clinical Practice: From development to use. National Academy Press, Washington, 1992.

29. Eddy DM. Comparing benefits and harms: the balance shifts. JAMA 1990; 263:2493-250.

30. Kosecoff J, Kanouse DE, Brook RH. Changing practice patterns in the management of primary breast cancer: consensus development programs. Health Serv Res 1990; 25:809-823.

31. Appelbaum PS. Practice guidelines in psychiatry and their implications for malpractice. Hosp Community Psychiatry 1992; 43:341-342.

32. Bulger RJ. Letter from the interest group on Health Services Research, Association of Academic Health Centers. JQI Jt Comm J Qual Improv 1993; 19:303304.

33. Kelly JT, Swartout JE. Development of practice parameters by physician organizations. QRB Qual Rev Bull 1990; 16:54-57.

34. Zhanel GG, Gin As, Przybylo A et al. Effect of interventions on prescribing of antimicrobials for prophylaxis in obstetric and gynecologic surgery. Am J Hosp Pharm 1989; 46:2493-2496.

35. Gottlieb LK, Margolis CA, Schoenbaum SC. Clinical practice guidelines at an HMO: development and implementation in a quality improvement model. $Q R B$ Qual Rev Bull 1990; 16:80-86.

36. Anderson GF, Lave JR, Russe CM. Providing hospital services: The changing financial environment. The John's Hopkins University Press, Baltimore, 1989.

37. Browman GP, Levine MN, Mohide EA et al. The practice guidelines development cycle: a conceptual tool for practice guidelines development and implementation. J Clin Oncol 1995; 13:502-512.

38. Robinson ML. Medical practice guidelines may affect payment. Hospitals 1988; 62:30-31.

39. Carr DB, Jacox AK, Chapman CR et al. Acute pain management: Operative or medical procedures and trauma: Clinical Practice Guideline. AHCPR Publi- cation 92-032. US Public Health Service, Agency for Health Care Policy and Research, Rockville, 1992.

40. Jacox A, Carr Db, Payne R et al. Management of Cancer Pain: Clinical practice guideline number 9. AHCPR Publication 94-0592. US Public Health Service, Agency for Health Care Policy and Research, Rockville, 1994.

41. Cancer pain relief. World Health Organization, Geneva 1986.

42. Ready LB, Edwards WT. Management of acute pain: A practical guide. International Association for the Study of Pain. IASP Publications, Seattle, 1992.

43. Ready LB. Practice guidelines for acute pain management in the perioperative setting: A report by the American Society of Anesthesiologists Task Force on Pain Management, Acute Pain Section. Anesthesiology 1995; 82:1071.

44. Bigos SJ, Boyer OR, Braen GR et al. Acute Low Back Problems in Adults. Clinical Practice Guideline Number 4. AHCPR Publication No. 95-0642. Agency for Health Care Policy and Research, Public Health Service, US Department of Health and Human Services, Rockville, December 1994.

45. Spitzer WO, Leblanc FE, Dupuis M (eds). Quebec Task Force on Spinal Disorders. Scientific approach to the assessment and management of activity-related spinal disorders: A monograph for clinicians. Spine 1987;(suppl)12:1-59.

46. Spitzer WO, Skovron ML, Salmi LR et al. Scientific monograph of the Quebec Task Force on whiplashassociated disorders: Redefining "whiplash” and its management. Spine 1995;20 (Suppl):1-73.

47. Nash TP. Current guidelines in the use of epidural steroids in the United Kingdom. Pain Digest 1999; 9:231-232.

48. Abram SE. Current guidelines in the use of epidural steroids in the United States of America. Pain Digest 1999; 9:233-234.

49. Manchikanti L, Singh V, Bakhit CE et al. Interventional techniques in the management of chronic pain. Part 1.0. Pain Physician 2000; 3:7-42.

50. Manchikanti L. Dr. No. Managed care. Clinical guidelines. Pain Physician 2000; 3:3-6.

51. Nunn CM. Pathways, guidelines, and cookbook medicine: Are we all becoming Betty Crocker? JCOM 1997;4:17-24.

52. The nonsurgical management of acute low back pain. Gonzalez EG, Materson (eds). Demos Vermane, New York, 1997.

53. Bogduk N, Christophidis N, Cherry D et al. Epidural use of steroids in the management of back pain. Report of working party on epidural use of steroids in the management of back pain. National Health and Medical Research Council. Canberra, Commonwealth of Australia, 1994, pp 1-76. 
54. Benzon HT, Molly RE. Outcomes, efficacy, and compliances from management of low back pain. In: Practical management of pain. Raj PP, Abrams BM, Benzon HT et al (eds), Third Edition, Mosby, Philadelphia 2000, pp 891-903.

55. Watts RW, Silagy CA. A meta-analysis on the efficacy of epidural corticosteroids in the treatment of sciatica. Anaesth Intens Care 1995; 23:564-569.

56. Koes BW, Scholten R, Mens JMA et al. Epidural steroid injections for low back pain and sciatica. An updated systematic review of randomized clinical trials. Pain Digest 1999; 9:241-247.

57. Van Zundert J, Plaghki L, Adriaensen H. Conclusions: Value of epidural corticosteroid injections in low back pain and sciatica. Pain Digest 1999; 9:248251.

58. American Geriatrics Society. The management of chronic pain in older persons: New Guidelines from the American Geriatrics Society. J Am Geriatr Soc 1998; 46:128-150.

59. Sanders SH, Harden RN, Benson SE et al. Clinical practice guidelines for chronic non-malignant pain syndrome patients II: An evidence-based approach. $J$ Back Musc Rehabil, 1999; 13:47-58.

60. Sanders SH, Rucker KS, Anderson KO et al. Clinical practice guidelines for chronic non-malignant pain syndrome patients. J Back Musc Rehabil, 1995; 5:115120.

61. Campbell JK, Penzine DB, Wall EM. Evidence-based guidelines for migraine headache: Behavioral and physical treatments. The US Headache Consortium, American Academy of Neurology, 1999. [Online]. Available: www.aan.com.

62. McCrory DC, Matchar DB, Gray RN et al. Evidencebased guidelines for migraine headache: Overview of program description and methodology. The US Headache Consortium, American Academy of Neurology, 1999a. [Online]. Available: www.aan.com.

63. McCrory DC, Matchar DB, Gray RN et al. Evidencebased guidelines for migraine headache: Pharmacological management for acute attacks and prevention of migraine. The US Headahce Consortium, American Academy of Neurology, 1999b. [Online]. Available: www.aan.com.

64. American Pain Society. Guideline for the management of acute and chronic pain in sickle-cell disease. American Pain Society, Glenview, 1999.

65. Stanton-Hicks M, Baron R, Boas R et al. Complex regional pain syndromes: Guidelines for therapy. Clin J Pain, 1998; 14:115-116.

66. Practice guidelines for chronic pain management. A report by the American Society of Anesthesiologists Task Force on Pain Management, Chronic Pain Section. Anesthesiology 1997; 86:995-1004.

67. Bogduk N. International Spinal Injection Society guidelines for the performance of spinal injection pro- cedures. Part 1: Zygapophyseal joint blocks. Clin J Pain 1997;13:285-302.

68. Waldman SD, Waldman KA, Siwek SM. Interventional Waldman SD (ed), pain management, programming for success: In Interventional pain management. Waldman SD (ed), Second Edition. W.B. Saunders Company, Philadelphia 2000; pp 79-82.

69. Godlee F. Clinical evidence, BMJ Publishing Group, London, June 2000; pp 486-572.

70. Chalmers I, Dickersin K, Chalmers TC. Getting to grips with Archie Cochrane’s agenda. Br Med J 1992; 305:786.

71. Manchikanti L. Appropriate documentation, billing and coding of interventional pain procedures. Pain Physician 2000; 3:218-237.

72. Butler L. Clinton budget boosts efforts to combat Medicare fraud. American Med News 2000; 43(7): 1, 34, 35.

73. Klein SA. Feds try new talk in charging doctors with upcoding. Am Med News 2000; 43(7): 5-6.

74. Manchikanti L. Signh V, Kloth D, et al. Interventional techniques in the management of chronic pain: Part 2.0. Pain Physician 2001; 4:24-96.

75. Battista RN, Hodge MJ. Clinical practice guidelines: between science and art. Can Med Assoc J 1993; 148:385.

76. Brook Robert H. Practice guidelines and practicing medicine. Are they compatible? JAMA 1989;262:3027-3030.

77. Shaneyfelt TM, Mayo-Smith MF, Rothwangl J. Are guidelines following guidelines? The methodological quality of clinical practice guidelines in the peerreviewed medical literature. JAMA 1999; 281:19001905.

78. Cabana MD, Rand, CS, Powe NR et al. Why don't physicians follow clinical practice guidelines? A framework for improvement. JAMA 1999; 282:14581465.

79. Marwick C. Will evidence-based practice help span gulf between medicine and law? JAMA 2000; 283:2775-2778.

80. Brennan T. Overview of legal issues. JQI Jt Comm J Qual Improv 1993; 19:319-321.

81. Chodoff P, Crowley K. Clinical practice guidelines: Roadblocks to their acceptance and implementation. J Out Manage 1995; 2:5.

82. Dans PE. Creditability, cookbook medicine and common sense: Guidelines and the college. Ann Intern Med 1994; 120:996-998.

83. Agency for Health Care Policy and Research, Center for Research Dissemination and Liasion. Conference on effect dissemination of clinical and health information. Tuscon, AZ, September 22-24, 1991.

84. Van Amringe M, Shannon TE. Awareness, assimilation, and adoption: the challenge of effective dissemination and the first AHCPR-sponsored guidelines. QRB Qual Res Bull 1992; 18:397-404. 
85. Tulder MWV, Assendelft JJ, Koes BW et al. Method guidelines for systematic reviews in the Cochrane collaboration back review group for spinal disorders. Spine 1997; 22:2323-2330.

86. Mugford HK. Conflicting conclusions from two systematic reviews of epidural steroid injections for sciatica: which evidence should general practitioners heed? Br J Gen Pract 1999; 49:57-61.

87. Sanders S. Integrating practice guidelines for chronic pain: From the Tower of Babel to the Rosetta Stone. APS bulletin 2000; 10:(6): 1-7.

88. Koes BW, Bouter LM, Van Der Heijden GJMGV. Methodological quality of randomized clinical trials on treatment efficacy in low back pain. Spine 1995;20:228-235.

89. Tulder MWV, Koes BW, Bouter LM. Conservative treatment of acute chronic nonspecific low back pain. A systematic review of randomized controlled trials of the most common interventions. Spine 1997; 22:2128-2156.

90. Fishbain D, Cutler RB, Rosomoff HL et al. What is the quality of the implemented meta-analytic procedures in chronic pain treatment meta-analyses? Clin J Pain 2000; 16:73-85.

91. Tulder MWV, Osteolo R, Vlaeyen JWS et al. Behavioral treatment for chronic low back pain. A systematic review within the framework of the Cochrane back review group. Spine 2000; 25:26882699.

92. Hazard RG, Reid S, Haugh LD et al. A controlled trial of an educational pamphlet to prevent disability after occupational low back injury. Spine 2000; 25:1419-1423.

93. Wassell JT, Gardner LI, Landsittel DP et al. A prospective study of back belts for prevention of back pain and injury. JAMA 2000; 284:2727-2732

94. Tulder MWV, Malmivaara A, Esmail R. Exercise therapy for low back pain. A systematic review within the framework of the Cochrane collaboration back review group. Spine 2000; 25:2784-2796.

95. Hansson TH, Hansson EK. The effects of common medical interventions on pain, back function, and work resumption in patients with chronic low back pain. Spine 2000; 25:3055-3064.

96. Ezzo J, Berman B, Hadhazy VA et al. Is acupuncture effective for the treatment of chronic pain? A systematic review. Pain 2000; 86:217-225.

97. Altmaier EM, Lehmann T, Russell DW et al. The effectiveness of psychological interventions for the rehabilitation of low back pain: A randomized controlled trial evaluation. Pain 1992; 49:329-335.

98. Bush C, Ditto B, Feurstein M. A controlled evaluation of paraspinal EMG biofeedback in the treatment of chronic low back pain. Health Psychol 1985; 4:307-321.

99. Donaldson S, Romney D, Donaldson M et al. Randomized study of the application of single motor unit biofeedback training to chronic low back pain. $J$ Occup Rehabil 1994; 4:23-37.

100. Lindström I, Öhlund C, Eek C et al. The effect of graded activity on patients with subacute low back pain: A randomized prospective clinical study with an operant-conditioning behavioral approach. Phys Ther 1992; 72:279-293.

101. Lindström I, Öhlund C, Eek C et al. Mobility, strength, and fitness after a graded activity program for patients with subacute low back pain: A randomized prospective clinical study with a behavioral therapy approach. Spine 1992; 17:641-652.

102. McCauley JD, Thelen MH, Frank RG et al. Hypnosis compared with relaxation in the outpatient management of chronic low back pain. Arch Phys Med Rehabil 1983; 64:548-552.

103. Newton-John T, Spence SH, Schotte D. Cognitivebehavioral therapy versus EMG biofeedback in the treatment of chronic low back pain. Behav Res Ther 1995; 33:691-697.

104. Nouwen A. EMG biofeedback used to reduce standing levels of paraspinal muscle tension in chronic low back pain. Pain 1983; 17:353-360.

105. Rose MJ, Reilly JP, Pennie B et al. Chronic low back pain rehabilitation programs: A study of the optimum duration of treatment and a comparison of group and individual therapy. Spine 1997; 22:2246-2253.

106. Koes BW, Assendelft WJJ, Heijden GJMG van der et al. Spinal manipulation and mobilization for back and neck pain: A blinded review. $\mathrm{Br}$ Med $\mathrm{J}$ 1991;303:1298-1303.

107. Koes BW, Bouter LM, Mameren H Van, et al. A blinded randomized clinical trial of manual therapy and physiotherapy for chronic back and neck complaints: Physical outcome measures. J Manipulative Physiol Ther 1992;1:16-23.

108. Mayer TG, Polatin P, Smith B et al. Spine rehabilitation. Secondary and tertiary nonoperative care. Spine 1995;20:2060-2066.

109. Teasell RW, Harth M. Functional restoration. Returning patients with chronic low back pain to workRevolution or fad? Spine 1996;21:844-847.

110. Van der Windt DAWM, van der Jeijden GJMG, van den Berg SGM et al. Ultrasound therapy for musculoskeletal disorders. A systematic review. Pain 1999; 81:257-271.

111. Hurwitz EL, Aker PD, Adams AH et al. Manipulation and mobilization of the cervical spine. A systematic review of the literature. Spine 1996; 21:17461760.

112. Cassisi JE, Sypert GW, Salamon A et al. Independent evaluation of a multidisciplinary rehabilitation program for chronic low back pain. Neurosurgery 1989; 25:877-883.

113. Robinson JP, Allen T, Fulton LD et al. Perceived efficacy of pain clinics in the rehabilitation of injured workers. Clin J Pain 1998; 14:202-208. 
114. Triano JJ, McGregor M, Hondras MA et al. Manipulative therapy versus education programs in chronic low back pain. Spine 1995; 20:469-472.

115. Mayer T, McMahon MJ, Gatchel RJ et al. Socioeconomic outcomes of combined spine surgery and functional restoration in workers' compensation spinal disorders with matched controls. Spine 1998; 23:598-606.

116. Wheeler AH, Hanley EN Jr. Nonoperative treatment for low back pain. Rest to restoration. Spine 1995; 20:375-378.

117. Morley S, Eccleston C, Williams A. Systematic review and meta-analysis of randomized controlled trials of cognitive behavior therapy for chronic pain in adults, excluding headache. Pain 1999; 90:1-13.

118. van Poppel MN, Koes BW, van der Ploeg $\mathrm{T}$ et al. Lumbar supports and education for the prevention of low back pain in industry: a randomized controlled trial. JAMA 1998; 279:1789-1794.

119. Weinstein JN. The tortoise and the hare. Is there a place in spine surgery for randomized trials? Spine 1999; 23:2548-2549.

120. Winter RB. The prospective, randomized, controlled clinical trial in spine surgery. Fact or fiction? Spine 1999; 23:2550-2552.

121. Carey TS. Randomized controlled trials in surgery. An essential component of scientific progress. Spine 1999; 23:2553-2555.

122. Fairbank J. Randomized controlled trials in the surgical management of spinal problems. Spine 1999; 23:2556-2563.

123. Tosteson TD. Point of view. Spine 1999; 24:25622563.

124. Turk DC, Okifuji A. Treatment of chronic pain patients. Clinical outcomes, cost-effectiveness, and cost- benefits of multidisciplinary pain centers. Crit Rev Phys Rehabil Med 1998; 10:181-208.

125. Concato J, Shah N, Horwitz RI. Randomized, controlled trials, observational studies, and the hierarchy of research designs. N Engl J Med 2000;342:18871892.

126. Schulz KF, Chalmers I, Hayes RJ et al. Empirical evidence of bias: dimensions of methodological quality associated with estimates of treatment effects in controlled trials. JAMA 1995; 273:408-412.

127. Mittan Bs, Tonesk X, Jacobson PD. Implementing clinical practice guidelines: social influence strategies and practitioner behavior change. QRB Qual Rev Bull 1992; 18:413-422.

128. Hayward RSA, Wilson MC, Tunis SR. Users' guides to the medical literature. VIII. How to use clinical practice guidelines. A. Are the recommendations valid? JAMA 1995; 274:570-574.

129. Lomas J, Haynes RB. A taxonomy in clinical review of tested strategies for the application of clinical practice recommendations: From "official” to "individual" clinical policy. Am J Prev Med 1988; 4:77-94.

130. Kosecoff J, Kanouse De, Rogers WH et al. Effects of the national institutes of health consensus development program on physician practice. JAMA 1987; 258:2708-2713.

131. Tunis SR, Hayward RSA, Wilson MC et al. Internists' attitudes about clinical practice guidelines. Ann Intern Med 1994; 120:956-963.

132. Asaph JW, Janoff K, Wayson K et al. Carotid endarterectomy in a community hospital: A change in physician's practice patterns. Am J Surg. 1991; 161: 616-618.

133. Herman R. Harvard HMO improves pap smear screening. QA Rev 1989; 1:2-3. 